\begin{tabular}{ll|l} 
Case Reports in & \multicolumn{2}{c}{ Case Rep Gastroenterol 2020;14:110-115 } \\
\cline { 2 - 3 } Gastroenterology & $\begin{array}{l}\text { DOl: 10.1159/000506361 } 2020 \text { The Author(s) } \\
\text { Published online: February 25, } 2020\end{array}$ & $\begin{array}{l}\text { Published by S. Karger AG, Basel } \\
\text { www.karger.com/crg }\end{array}$ \\
\cline { 2 - 2 } & $\begin{array}{l}\text { This article is licensed under the Creative Commons Attribution-NonCommercial } 4.0 \\
\text { International License (CC BY-NC) (http://www.karger.com/Services/OpenAccessLicense). } \\
\text { Usage and distribution for commercial purposes requires written permission. }\end{array}$
\end{tabular}

\title{
Identifying Cystic Vein Perfusion Area Employing Indocyanine Green Fluorescence Imaging during Laparoscopic Extended Cholecystectomy for Clinical T2 Gallbladder Cancer
}

\author{
Akira Umemura Hiroyuki Nitta Takeshi Takahara Yasushi Hasegawa \\ Hirokatsu Katagiri Shoji Kanno Taro Ando Megumi Kobayashi \\ Akira Sasaki \\ Department of Surgery, Iwate Medical University, Yahaba, Japan
}

\section{Keywords}

Gallbladder cancer - Indocyanine green fluorescence - Extended cholecystectomy .

Gallbladder bed resection - Laparoscopic hepatectomy

\begin{abstract}
We present an original surgical technique for identifying the perfusion area of the cystic vein with indocyanine green (ICG) fluorescence imaging and laparoscopic extended cholecystectomy with lymphadenectomy for a 56-year-old woman with diagnosis of clinical T2 gallbladder cancer (GBC). First, we encircled Calot's triangle using the Glissonean approach from the ventral side of the gallbladder plate and then taped the hilar Glissonean pedicles; these were temporally clamped, and ICG was injected into the vein. The perfusion area of the cystic vein was scrutinized, specifically the stained area of the hepatic parenchyma was marked, and extended cholecystectomy was performed along the resection line. Subsequently, we performed lymphadenectomy of the hepatoduodenal ligament to complete the operation. A postoperative histopathological examination revealed moderately differentiated adenocarcinoma with pathological T1bNOM0. Although extended cholecystectomy is currently recommended for clinical T2 GBC, there is no consensus on the definition of the gallbladder bed, and the ideal extent of
\end{abstract}




\section{Case Reports in Gastroenterology}

Case Rep Gastroenterol 2020;14:110-115

DOI: $10.1159 / 000506361$

c) 2020 The Author(s). Published by S. Karger AG, Basel www.karger.com/crg

Umemura et al.: Laparoscopic ICG Imaging of Cystic Vein Perfusion Area during GBC Surgery

hepatic resection has, therefore, not yet been determined. In addition, gallbladder bed resection with $2-3 \mathrm{~cm}$ of surgical margin is an empirical procedure that lacks scientific verification. Regarding anatomical features, the cystic vein sometimes drains directly into the anterior branch of the portal vein, penetrating the gallbladder plate and Laennec's capsule of the anterior Glissonean pedicle. To address this background, we have developed a technique to identify the perfusion area of the cystic vein to determine the extent of hepatic parenchyma that should be resected during laparoscopic extended cholecystectomy for clinical T2 GBC.

(C) 2020 The Author(s)

Published by S. Karger AG, Basel

\section{Introduction}

Curative radical surgery is the gold standard treatment for gallbladder cancer (GBC) according to current consensus, and the depth of tumor invasion is an essential factor in determining the extent of appropriate resection [1]. For clinical T2 GBC, extended cholecystectomy, consisting of cholecystectomy and gallbladder bed resection, and regional lymphadenectomy of the hepatoduodenal ligament is the recommended procedure [2]. However, a strict definition of the gallbladder bed in the liver has not yet been clarified, and surgeons therefore perform extended cholecystectomy without any clear indication of the hepatic parenchyma that should be resected [3]. Against this background, we employed indocyanine green (ICG) fluorescence imaging to identify the perfusion area of the cystic vein for the purpose of determining the distinguishing features of the gallbladder bed. In this case report, we present an original surgical technique for identifying the perfusion area of the cystic vein and for laparoscopic extended cholecystectomy with lymphadenectomy for clinical T2 GBC.

\section{Case Presentation}

A 56-year-old woman presented with intermittent abdominal pain and attended hospital to undergo further investigation. Her laboratory data, including tumor markers, were almost within the normal range. An abdominal computed tomography workup revealed a right renal tumor about $4 \mathrm{~cm}$ in size and another tumor located from the body of the gallbladder to its neck (Fig. 1a, b). T2-weighted magnetic resonance imaging revealed the right renal tumor, and magnetic resonance cholangiopancreatography revealed a defect of the gallbladder neck (Fig. 1c, d). Although endoscopic bile juice cytology could not certify malignancy, she was diagnosed as having both GBC with clinical T2N0M0 and right renal cell carcinoma with clinical T1aN0M0. Following these preoperative investigations, we performed laparoscopic extended cholecystectomy with lymphadenectomy for the GBC, and robotic partial nephrectomy was planned for after recovery.

The patient was put in a supine position under general anesthesia, and the operation was initiated using a five-port approach. During hepatic parenchymal transection, the upper limit for pneumoperitoneum pressure was set to $12 \mathrm{~mm}$ Hg. First, we encircled Calot's triangle using the Glissonean approach from the ventral side of the gallbladder plate, and then taped the hilar Glissonean pedicles to prevent inflow from the proper hepatic artery without cystic artery flow (Fig. 2a). Then, the hilar Glissonean pedicles were temporarily clamped, and $2.5 \mathrm{mg}$ of ICG was injected into the vein for scrutiny of the perfusion area of the cystic vein. The demarcation of stained areas within the hepatic parenchyma was marked by electrocautery to determine the transecting line (Fig. 2b). The cystic duct and cystic artery were cut at Calot's 


\section{Case Reports in Gastroenterology}

Case Rep Gastroenterol 2020;14:110-115

DOI: 10.1159/000506361

c) 2020 The Author(s). Published by S. Karger AG, Basel www.karger.com/crg

Umemura et al.: Laparoscopic ICG Imaging of Cystic Vein Perfusion Area during GBC Surgery

triangle, and hepatic parenchymal transection was performed along the demarcation lines employing Pringle's maneuver. The gallbladder and the hepatic parenchyma of its bed were resected en bloc (Fig. 2c). Subsequently, we performed lymphadenectomy of the hepatoduodenal ligament (Fig. 2d), and the operation was complete. The operating time was $191 \mathrm{~min}$ and blood loss was $57 \mathrm{~mL}$; no transfusion was required.

Drains remained in place for 2 days, and the patient was discharged on postoperative day 7. Postoperative histopathological examination revealed moderately differentiated adenocarcinoma with pathological T1bN0M0. The patient did not require adjuvant chemotherapy for this GBC; accordingly, she was referred to the urologist for the planned robotic partial nephrectomy.

\section{Discussion}

Patients with GBC have various clinical presentations that require different surgical extents - from small polypoid lesions to large masses that invade the gallbladder bed, hepatic hilum, or other adjacent organs. In addition, advanced GBC sometimes requires vessel reconstruction or hepatopancreaticoduodenectomy to secure R0 resection. For clinical T1b-T3 GBC, extended cholecystectomy or S4aS5 hepatectomy is recommended, although some opinions hold that S4aS5 hepatectomy has no significant advantage in prognosis compared with extended cholecystectomy [4]. However, although usual gallbladder bed resection employs a surgical margin of 2-3 cm from the gallbladder bed, there is no clear consensus on the definition or ideal extent of hepatic resection in extended cholecystectomy. To address this, we have developed a technique to identify the perfusion areas of the cystic vein to determine the features of the hepatic parenchyma that should be resected. We introduced this technique in four cases and were able to identify the perfusion area in three, including the present case. Using ICG, we found variety in the stained area (Fig. 3a-d), and determining the appropriate extent of the gallbladder bed is therefore essential in performing radical extended cholecystectomy.

Fluorescence imaging using ICG has become widespread as an intraoperative navigation tool to detect lymphatic and blood flows and hepatobiliary structures during surgeries [5]. In this technique, the most important procedures are the selective encircling of Calot's triangle employing a Glissonean approach, the swift identification of Laennec's capsule, and the preservation of the layer between Laennec's capsule and the gallbladder plate. The laparoscopic Glissonean approach requires extensive knowledge and technique of laparoscopic hepatectomy [6], and surgeons must also adopt an unusual angle and route to encircle Calot's triangle. We have introduced the technique smoothly by building on the accumulation of laparoscopic hepatectomies [7].

The theoretical mechanism of hepatic spread of GBC includes direct invasion, hematogenous metastasis, and lymphatic transmission [8]. Currently, extended cholecystectomy is performed with three aims: (1) to achieve a negative resection margin, (2) to prevent local recurrence near the gallbladder bed, and (3) to prevent potential invasion of the hepatoduodenal ligament via the right Glissonean sheath and gallbladder plate [3]. Although intrahepatic spread of GBC via the cystic vein is currently not a mainstream consideration because of the histopathological lymphatic spread via the Glissonean sheath to the hilar plate, $25 \%$ of perfusion flow from the cystic vein is anatomically confluent to the anterior branch of the portal vein [9]. If Laennec's capsule completely bridges the Glissonean sheath and hepatic vein, these anatomical connections must be a critical pitfall of the Laennec's capsule concept. Given these contradictions, defining the perfusion area of the cystic vein as the gallbladder bed that should 
be resected during extended cholecystectomy is justifiable. Furthermore, our novel laparoscopic ICG imaging for identifying the perfusion area of the cystic vein is a useful technique.

In conclusion, extended radical cholecystectomy is currently indicated for clinical T2 GBC patients with or without localized hepatic invasion. The cystic vein sometimes drains directly into the anterior branch of the portal vein, penetrating the gallbladder plate and Laennec's capsule of the anterior Glissonean pedicle; therefore, the appropriate hepatic parenchyma for resection must be strictly clarified. Our technique is useful in identifying the perfusion area of the cystic vein and defining the extent of the gallbladder bed.

\section{Statement of Ethics}

The authors have no ethical conflicts to disclose. Informed consent was obtained from the presented patient.

\section{Disclosure Statement}

The authors declare no financial conflicts of interest.

\section{Funding Sources}

This work received no funding.

\section{Author Contributions}

A. Umemura and H. Nitta are the primary investigators in this case report and contributed to conceptualization, data collection, and drafting of the manuscript. All authors read and approved the manuscript for publication.

\section{References}

1 Miyazaki M, Yoshitomi H, Miyakawa S, Uesaka K, Unno M, Endo I, et al. Clinical practice guidelines for the management of biliary tract cancers 2015: the 2nd English edition. J Hepatobiliary Pancreat Sci. 2015 Apr; 22(4):249-73.

2 Aloia TA, Járufe N, Javle M, Maithel SK, Roa JC, Adsay V, et al. Gallbladder cancer: expert consensus statement. HPB (Oxford). 2015 Aug;17(8):681-90.

3 Cho JK, Lee W, Jang JY, Kim HG, Kim JM, Kwag SJ, et al. Validation of the oncologic effect of hepatic resection for T2 gallbladder cancer: a retrospective study. World J Surg Oncol. 2019 Jan;17(1):8.

4 Han HS, Yoon YS, Agarwal AK, Belli G, Itano 0, Gumbs AA, et al. Laparoscopic Surgery for Gallbladder Cancer: An Expert Consensus Statement. Dig Surg. 2019;36(1):1-6.

5 Ishizawa T, Saiura A, Kokudo N. Clinical application of indocyanine green-fluorescence imaging during hepatectomy. Hepatobiliary Surg Nutr. 2016 Aug;5(4):322-8.

6 Hasegawa Y, Nitta H, Takahara T, Katagiri H, Kanno S, Sasaki A. Pure laparoscopic living donor hepatectomy using the Glissonean pedicle approach (with video). Surg Endosc. 2019 Aug;33(8):2704-9.

7 Takahara T, Wakabayashi G, Nitta H, Hasegawa Y, Katagiri H, Takeda D, et al. Laparoscopic liver resection for hepatocellular carcinoma with cirrhosis in a single institution. Hepatobiliary Surg Nutr. 2015 Dec;4(6): 398-405. 


\section{Case Reports in Gastroenterology}

\begin{tabular}{l|l}
\hline Case Rep Gastroenterol 2020;14:110-115 \\
\hline DOI: 10.1159/000506361 & $\begin{array}{l}\text { @ 2020 The Author(s). Published by S. Karger AG, Basel } \\
\text { www.karger.com/crg }\end{array}$ \\
\hline
\end{tabular}

Umemura et al.: Laparoscopic ICG Imaging of Cystic Vein Perfusion Area during GBC Surgery

8 Wakai T, Shirai Y, Sakata J, Nagahashi M, Ajioka Y, Hatakeyama K. Mode of hepatic spread from gallbladder carcinoma: an immunohistochemical analysis of 42 hepatectomized specimens. Am J Surg Pathol. 2010 Jan; 34(1):65-74.

9 Sugita M, Ryu M, Satake M, Kinoshita T, Konishi M, Inoue K, et al. Intrahepatic inflow areas of the drainage vein of the gallbladder: analysis by angio-CT. Surgery. 2000 Sep;128(3):417-21.
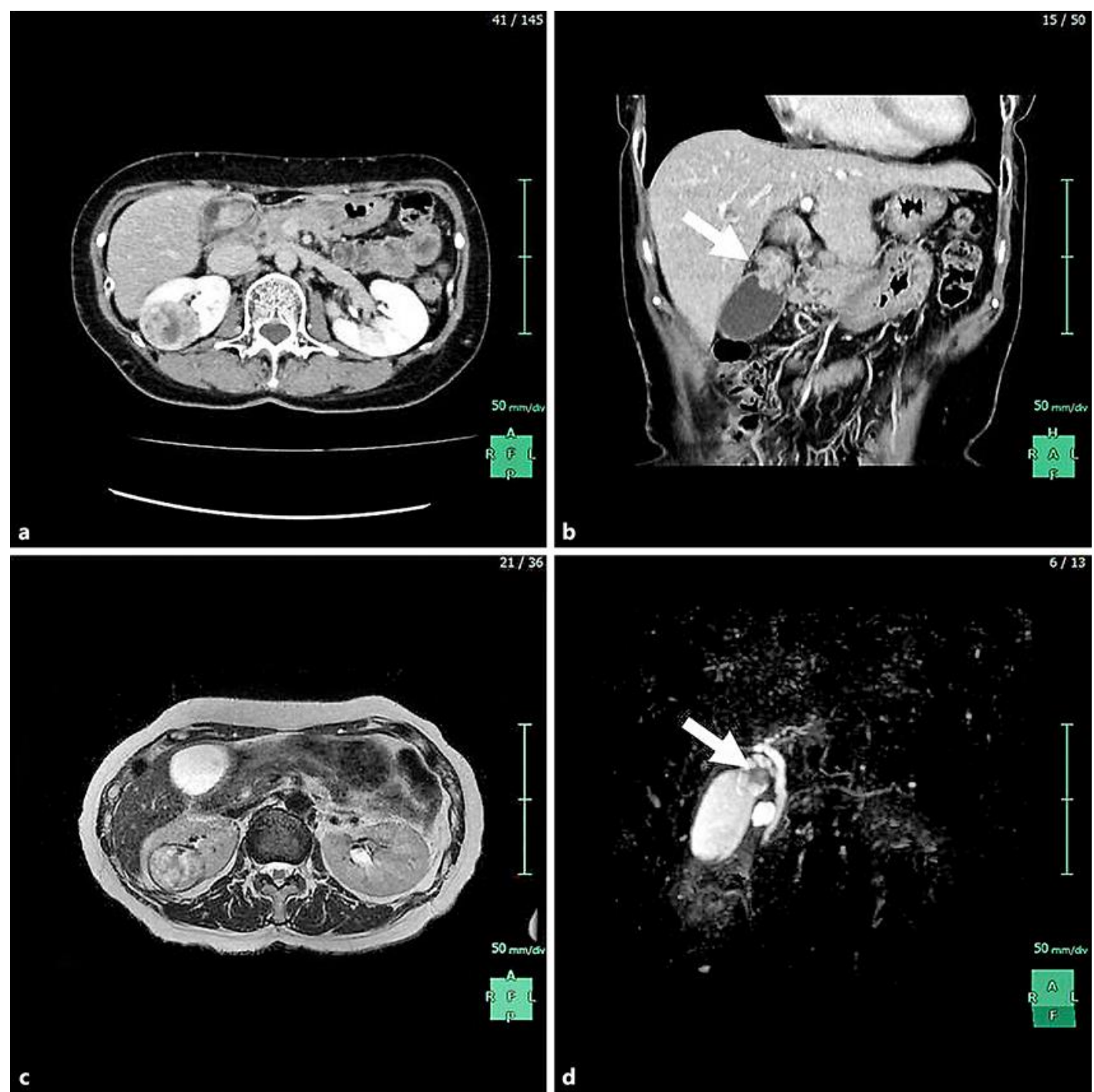

Fig. 1. a, b Contrast-enhanced computed tomography revealed a right renal tumor and gallbladder tumor of the neck. The enhanced gallbladder tumor did not invade into the hepatic parenchyma (arrow). c, d Magnetic resonance imaging of T2-weighted image revealed a clearly capsulized renal tumor of the right kidney, and magnetic resonance cholangiopancreatography also revealed the defect of the gallbladder neck (arrow). 


\section{Case Reports in Gastroenterology}

\begin{tabular}{l|l}
\hline Case Rep Gastroenterol 2020;14:110-115 \\
\hline DOI: 10.1159/000506361 & $\begin{array}{l}\text { C 2020 The Author(s). Published by S. Karger AG, Basel } \\
\text { www.karger.com/crg }\end{array}$ \\
\hline
\end{tabular}

Umemura et al.: Laparoscopic ICG Imaging of Cystic Vein Perfusion Area during GBC Surgery
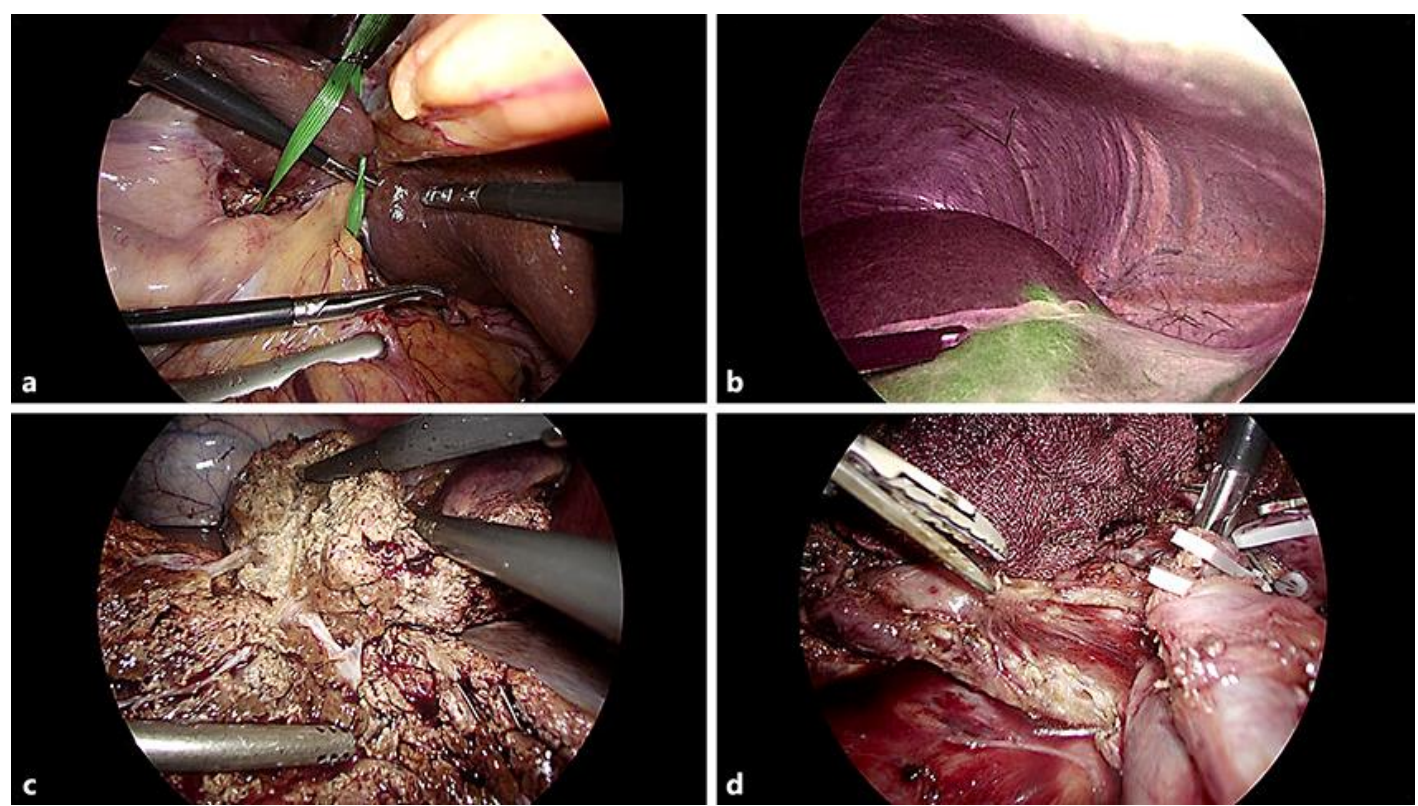

Fig. 2. Operative procedure. a The hilar Glissonean pedicle was taped to clamp the inflow from the proper hepatic artery without cystic artery flow. b Under ICG mode, the stained area of the hepatic parenchyma was marked by electrocautery to identify the perfusion area of the cystic vein. $\mathbf{c}$ Extended cholecystectomy was performed along the demarcation line. $\mathbf{d}$ We performed lymphadenectomy of the hepatoduodenal ligament. ICG, indocyanine green.
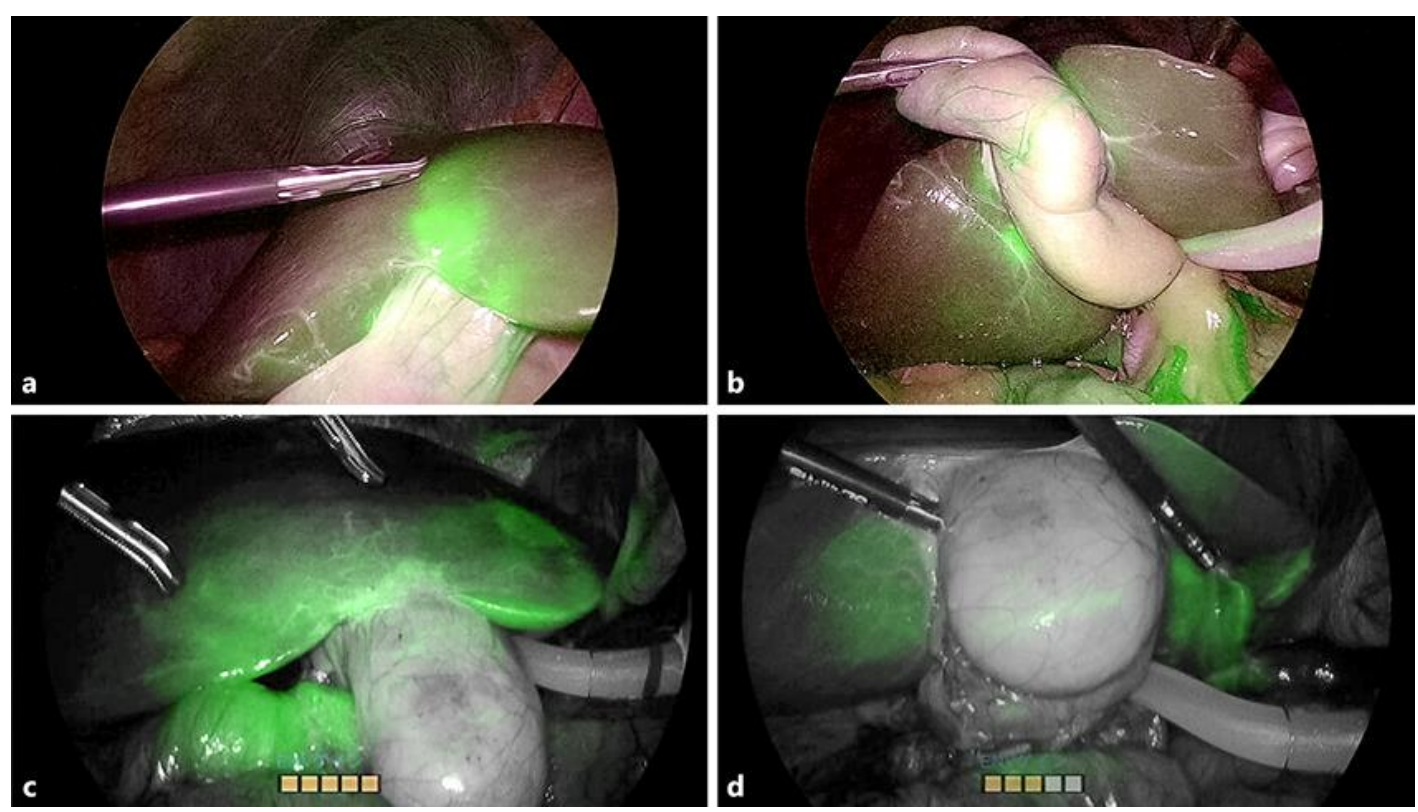

Fig. 3. a, b This patient was a living donor for liver transplantation. The stained area of this patient was dominant in S4a. c, $\mathbf{d}$ This patient was also a living donor for liver transplantation. The cystic vein of this patient covered the broad perfusion area from S4a to S5. 